\title{
Adaptation fermentation of Pichia stipitis and combination detoxification on steam exploded lignocellulosic prehydrolyzate
}

\author{
Jun-Jun Zhu ${ }^{1}$, Qiang Yong ${ }^{1}$, Yong Xu ${ }^{1}$, Shang-Xing Chen ${ }^{2}$, Shi-Yuan Yu ${ }^{1^{*}}$ \\ ${ }^{1}$ Ministry of Education, Key Laboratory of Forest Genetics \& Biotechnology, Nanjing Forestry University, Nanjing 210037, China; \\ ${ }^{2}$ College of Forestry, Jiangxi Agricultural University, Nanchang 330045, China. ${ }^{*}$ Corresponding author: Tel: +86 25 85427255; Fax: \\ +862585418873 . \\ E-mail: ${ }^{*}$ shiyuanyu.nfu@gmail.com
}

Received 25 May 2009; revised 5 June 2009; accepted 8 June 2009.

\section{ABSTRACT}

Yeast Pichia stipitis CBS 5776 was developed through adaptation fermentation step by step in steam exploded corn stover prehydrolyzate because high concentration of weak acids and other inhibitors present in the prehydrolyzate could degrade the fermentability. However, the adaptability of Pichia stipitis CBS 5776 in the prehydrolyzate was so limited that steam stripping and overliming were applied to remove these inhibitors from it. Corn stover was steam exploded; the filtrate of steam exploded corn stover was hydrolyzed with dilute sulfuric acid, and then the acid hydrolyzate was detoxified and fermented by Pichia stipitis CBS 5776. Steam stripping could remove volatile compounds from the acid hydrolyzate and the filtrate. At a steam stripping time of $120 \mathrm{~min}, 81 \%$ acetic acid and $59 \%$ formic acid were removed from the acid hydrolyzate, $77 \%$ acetic acid and $45 \%$ formic acid were removed from the filtrate, while furfural was stripped off completely from the acid hydrolyzate and the filtrate. Overliming could reduce the contents of furfural and phenolics present in the acid hydrolyzate, however, sugars, especially pentoses, were also removed partially. It was necessary to detoxify the acid hydrolyzate in order to ferment the sugars to ethanol. Acid hydrolyzate detoxified with a combination of steam stripping for $120 \mathrm{~min}$ and overliming at $\mathrm{pH} 11$ and $60^{\circ} \mathrm{C}$ for $90 \mathrm{~min}$, its fermentability was significantly improved. Xylose was consumed nearly completely in $24 \mathrm{~h}$ with an ethanol yield of $15.92 \mathrm{~g} / \mathrm{l}, \mathbf{8 0 . 3 4 \%}$ of theoretical.

Keywords: Steam Explosion; Steam Stripping; Overliming; Inhibitor; Acid Hydrolyzate

\section{INTRODUCTION}

For several decades, ethanol has been promoted as a promising alternative fuel for transportation. The use of fossil fuels has contributed to the buildup of carbon dioxide in the atmosphere; however ethanol is a cleanburning fuel that makes no net contribution to global warming because the carbon dioxide produced by the combustion of ethanol is consumed by plant growth which continues the carbon cycle balance in the nature. Ethanol can be produced from any material containing simple or complex sugars, such as sugar cane and various starchy materials (corn, wheat, and potatoes). However, the most promising raw material is represented by lignocellulose because of its renewable nature, abundance and low cost [1].

Lignocelluloses are mainly comprised of cellulose, hemicellulose, and lignin. The substrate must be pretreated so that it is more amenable to conversion. A number of pretreatments such as dilute acid hydrolysis [2], alkali treatment [3], sodium sulphite treatment [4], steam explosion [5], ammonia fiber explosion [6], lime treatment [7], wet oxidation [8], liquid hot water pretreatment [9], organic solvent treatment [10], and biologial pretreatment [11], and so on, have been used frequently to improve the saccharification of the carbohydrates. Of these methods, steam explosion has been recognized as one of the most cost- effective and potential pretreatment methods $[12,13]$. During the pretreatment process with high temperature, a part of cellulose, hemicellulose and lignin is degraded to produce compounds which inhibit enzymatic hydrolysis and ethanol fermentation. The main degraded products from steam exploded corn stover have been identified by HPLC and GC-MS analysis [14].

The inhibiting compounds are divided into three main groups based on origin: weak acids, furan derivatives, and phenolic compounds. Weak acids (formic, acetic, and levulinic acid), furan derivatives (furfural, 5-hy- 
droxymethylfurfural) from sugar degradation, phenol compounds from lignin degradation are considered to be potential fermentation inhibitors from pretreated lignocellulose [15]. In order to improve the fermentability of yeast, it can be done from the following two aspects, one is to make the yeast to adapt to the prehydrolyzate step by step, and another is to adopt methods to remove the inhibitors from the prehydrolyzate. Nigam investigated a mutant Pichia stipitis NRRL Y-7124 to adapt in acid hydrolyzate. When it was tested for its ability to ferment acid hydrolyzate, it showed shorter fermentation time, better tolerance to acid and could ferment at lower $\mathrm{pH}$. The ethanol yield and productivity were increased 1.3 and 2.1 fold, respectively [16]. However, more researchers investigated detoxification methods to detoxify the hydrolyzate to improve fermentation efficiency. Detoxification methods include neutralization [17], overliming [18], steam stripping [19], ion-exchange [20], treatment with activated carbon [20], wood charcoal [21], and laccase and peroxidase [22]. In many instances, the most economical and widely used method of detoxification involves treatment of hydrolyzates with solid calcium hydroxide [23]. This process of "overliming" is reported as an effective method of reducing toxicity of various hydrolyzates [24]. However, different yeasts endure the ability of inhibitors differently. Previous investigation in this laboratory indicated that only "overliming" was not an effective method to detoxify hydrolyzate fermented by Yeast Pichia stipitis CBS 5776 (data not shown), probably because overliming could not remove acetic and formic acid which inhibited the fermentability.

In this work, Pichia stipitis CBS 5776 was adapted in the filtrate with addition of xylose $30 \mathrm{~g} / 1$ step by step, and at the same time, steam stripping was firstly used to remove the volatile compounds such as formic and acetic acid in the acid hydrolyzate or filtrate, then overliming was performed to remove more other inhibitors. Xylose was added up to $45 \mathrm{~g} / 1$ to three kinds of hydrolyzates, undetoxified hydrolyzate, the hydrolzyate treated with steam stripping, and the hydrolyzate treated with a combination of steam stripping and overliming. The fermentabilities of the three kinds of hydrolyzates with yeast Pichia stipitis CBS 5776 were investigated.

\section{MATERIALS AND METHODS}

\subsection{Preparation of Acid Hydrolyzate}

Corn stover was obtained from Zhaodong city, Heilongjiang Province, China. The main composition of the raw material was (w/w\% of the dry weight): glucan, 40.10; xylan, 22.30; and lignin, 18.80. The corn stover was crushed to a granularity of 3 to $5 \mathrm{~cm}$, and then steam treated at $1.8 \mathrm{MPa}$ for $5 \mathrm{~min}$ before explosion. After steam explosion, $100 \mathrm{~g}$ (dry weight) exploded corn stover was washed and filtered three times with $1 \mathrm{~L}$ distilled water.
The filtrate was then hydrolyzed with dilute sulfuric acid $30 \mathrm{~g} / \mathrm{l}$ at $121^{\circ} \mathrm{C}$ for $45 \mathrm{~min}$.

\subsection{Detoxification of the Acid Hydrolyzate and the Filtrate}

The acid hydrolyzate or the filtrate was heated to boiling and kept at $100^{\circ} \mathrm{C}$. Steam was then put into the bottom of the vessel with a distributor to perform stripping. Steam stripping was operated for $15,30,45,60,90$, and 120 min, respectively.

Overliming was carried out by initially adjusting the $\mathrm{pH}$ of the acid hydrolyzate to $\mathrm{pH} 9,10$ and 11 , respectively, using solid calcium hydroxide. The samples were then heated to 40 or $60^{\circ} \mathrm{C}$ in a water bath for $90 \mathrm{~min}$ followed by centrifuging at $5000 \mathrm{rpm}$ for $10 \mathrm{~min}$. The upper liquid was collected and stored at $4^{\circ} \mathrm{C}$.

A combination of steam stripping and overliming was also performed for detoxification of the acid hydrolyzate. The hydrolyzate was firstly detoxified by steam stripping as described above; the sample's volume was adjusted to its original volume by the addition of water. The sample was then detoxified by overliming procedure.

\subsection{Yeast Strain and Media}

The yeast Pichia stipitis CBS 5776 was conserved in Nanjing Forestry University. It was maintained at $4^{\circ} \mathrm{C}$ in a medium containing $(\mathrm{g} / \mathrm{l})$ : xylose, 20 ; yeast extract, 5 ; peptone, 3; and agar, 20.

Inoculation medium contained $30 \mathrm{~g} / \mathrm{l}$ xylose, $5 \mathrm{~g} / \mathrm{l}$ peptone and $3 \mathrm{~g} / \mathrm{l}$ yeast extract at natural $\mathrm{pH}$. Multiplication medium was similar to the inoculation medium. The xylose fermentation medium was described previously by $\mathrm{Yu}[25]$.

Inoculum was prepared in $250 \mathrm{ml}$ shaking flask with $100 \mathrm{ml}$ medium, and incubated on a rotary shaker at 170 rpm and $30^{\circ} \mathrm{C}$ for several batches (24 hours per batch). When the optical density (OD) of yeast cells reached 10 , the cells were harvested by centrifugation, and the pellet was inoculated into the fermentation media.

\subsection{Adaptable Fermentation}

Adaptation medium was prepared by adding $30 \mathrm{~g} / \mathrm{l}$ xylose and the other compositions were described by $\mathrm{Yu}$ [25] in $10 \%, 20 \%, 30 \%, 40 \%$ and $50 \%(\mathrm{v} / \mathrm{v})$ filtrate of steam exploded corn stover.

The cells from inoculum preparation were firstly inoculated into $100 \mathrm{ml}$ of the adaptation fermentation medium of $10 \%$ filtrate in $250 \mathrm{ml}$ shaking flask at $30^{\circ} \mathrm{C}$ on a rotary shaker at $150 \mathrm{rpm}$ for $22 \mathrm{~h}$, then repeated fermentation of $10 \%$ filtrate for two times, finally the cells was inoculated into $20 \%, 30 \%, 40 \%$ and $50 \%$ filtrate and fermented for three times, respectively. 


\subsection{Fermentation of the Detoxified and Undetoxified Acid Hydrolyzates}

Three acid hydrolyzate preparations, namely the hydrolyzate without detoxification, the hydrolyzate treated with steam stripping only, and the hydrolyzate treated with a combination of steam stripping and overliming, were used for fermentation.

The $\mathrm{pH}$ of the hydrolyzate preparations was adjusted to 5.5 by the addition of $\mathrm{Ca}(\mathrm{OH})_{2}$ or $\mathrm{H}_{2} \mathrm{SO}_{4}$. The hydrolyzate preparations were then centrifuged at $5000 \mathrm{rpm}$ for 10min; the upper liquids were collected and stored at $4^{\circ} \mathrm{C}$. Xylose $45 \mathrm{~g} / 1$ was added to the three hydrolyzate preparations as the sugar sources. Fermentation was carried out in $250 \mathrm{ml}$ shaking flask with $100 \mathrm{ml}$ medium, and incubated on a rotary shaker at $150 \mathrm{rpm}$ and $30^{\circ} \mathrm{C}$.

\subsection{Analysis}

Sugars (cellobiose, glucose, xylose, and arabinose), fermentation products (ethanol, xylitol, glycerol) and inhibitors (formic acid, acetic acid, levulinic acid, 5-hydroxymethylfurfural, and furfural) were determined by high performance liquid chromatography (HPLC) using an Agilent 1100 system and refractive index detector. Separations were performed on a Bio-rad Aminex HPX$87 \mathrm{H}$ column $(300 \times 7.8 \mathrm{~mm}$ i.d. $)$ at $55^{\circ} \mathrm{C}$ using $0.005 \mathrm{~mol} / 1$ sulfuric acid as the mobile phase $(0.6 \mathrm{ml} / \mathrm{min})$. All the compounds were determined by ESTD methods.

The optical density (OD) of the yeast was measured spectrophotometrically at $600 \mathrm{~nm}$.

Spectrophotometric analysis of the hydrolyzate was performed using an Amersham Biosciences Ultrosepc 2100 pro UV/visible spectrophotometer. The hydrolyzates were diluted 100 times for measurements at $280 \mathrm{~nm}$.

\section{RESULTS AND DISCUSSION}

\subsection{Compositions of the Filtrate and the Acid Hydrolyzate from Steam Exploded Corn Stover}

Cellulose, hemicellulose, lignin and extractives in the corn stover were partially degraded and decomposed during steam explosion pretreatment [26]. The soluble degraded products included sugars (glucose, xylose, and arabinose) and inhibitory compounds (formic acid, acetic acid, levulinic acid, 5-hydroxymethylfurfural, furfural, and so on). Soluble oligosaccharides were also found in the filtrate because they could not be entirely degraded to monosaccharides during steam explosion, and they could not be fermented to ethanol by yeasts; therefore $30 \mathrm{~g} / \mathrm{l}$ sulfuric acid was applied to hydrolyzate the oligosaccharides to monosaccharides such as glucose and xylose at $121^{\circ} \mathrm{C}$ for $45 \mathrm{~min}$. The contents of the filtrate and the acid hydrolyzate from steam exploded corn stover were analyzed with HPLC and were shown in Table 1.
From Table 1, it could be seen that the concentration of xylose increased more than that of glucose, this indicated that xylooligosaccharides was more easily hydrolyzed to monosaccharides than cellooligosaccharides. After acid hydrolysis of the filtrate, formic acid, acetic acid and 5-hydroxymethylfurfural were decreased partially; however, levulinic acid and furfural were increased. The changes of inhibitors in the filtrate showed that a series of degradation reactions were occurred during the process of the acid hydrolysis.

\subsection{Adaptation Fermentation}

Since the sugar contents in the filtrate was too low, 30 $\mathrm{g} / 1$ xylose was added to the adaptation media containing $10 \%, 20 \%, 30 \%, 40 \%$, and $50 \%$ filtrate. Adaptation of the yeast Pichia stipitis CBS 5776 was achieved in the adaptation medium. Firstly, Pichia stipitis CBS 5776 was fermented on the adaptation medium of $10 \%$ filtrate for three times, after each fermentation, the centrifuging yeast was inoculated in the fresh adaptation medium; secondly, the yeast was inoculated in the adaptation medium of $20 \%$ filtrate for three times. The adaptation sequence was continued gradually until the adaptation medium of 50\% filtrate. Fig. 1 presented that the changes of the concentrations of residue xylose, fermentation product ethanol, the main fermentation by-product xylitol adapted fermentation in $10 \%, 20 \%, 30 \%, 40 \%$, and $50 \%$ filtrate for three times by Pichia stipitis CBS 5776.

As shown in Fig. 1, the concentration of residue xylose was increased from 0 in the $10 \%$ and $20 \%$ filtrate to $19.54 \mathrm{~g} / 1$ (means of triplicate) in the $50 \%$ filtrate with the increasing concentration of the filtrate. The fermentation product ethanol was firstly a little increased, and then decreased linearly; the maximum concentration of ethanol was $11.59 \mathrm{~g} / \mathrm{l}$ (means of triplicate) in the $20 \%$ filtrate. The fermentation by-product xylitol was decreased firstly and then increased a little; the maximum concentration of xylitol was $0.95 \mathrm{~g} / 1$ (means of triplicate) in the $10 \%$ filtrate.

Table 1. Contents of the filtrate and acid hydrolyzate from steam exploded corn stover.

\begin{tabular}{lcc}
\hline \multirow{2}{*}{ Compounds } & \multicolumn{2}{c}{ Concentration $(\mathrm{g} / \mathrm{l})$} \\
\cline { 2 - 3 } & The filtrate & $\begin{array}{c}\text { The acid } \\
\text { hydrolyzate }\end{array}$ \\
\hline Cellobiose & 0.33 & 0.12 \\
Glucose & 0.30 & 1.27 \\
Xylose & 0.79 & 2.13 \\
Arabinose & 0.27 & 0.29 \\
Formic acid & 2.07 & 1.82 \\
Acetic acid & 2.03 & 1.93 \\
Levulinic acid & 0.12 & 0.19 \\
5-hydroxymethylfurfural & 0.15 & 0.09 \\
Furfural & 0.10 & 0.18 \\
\hline
\end{tabular}



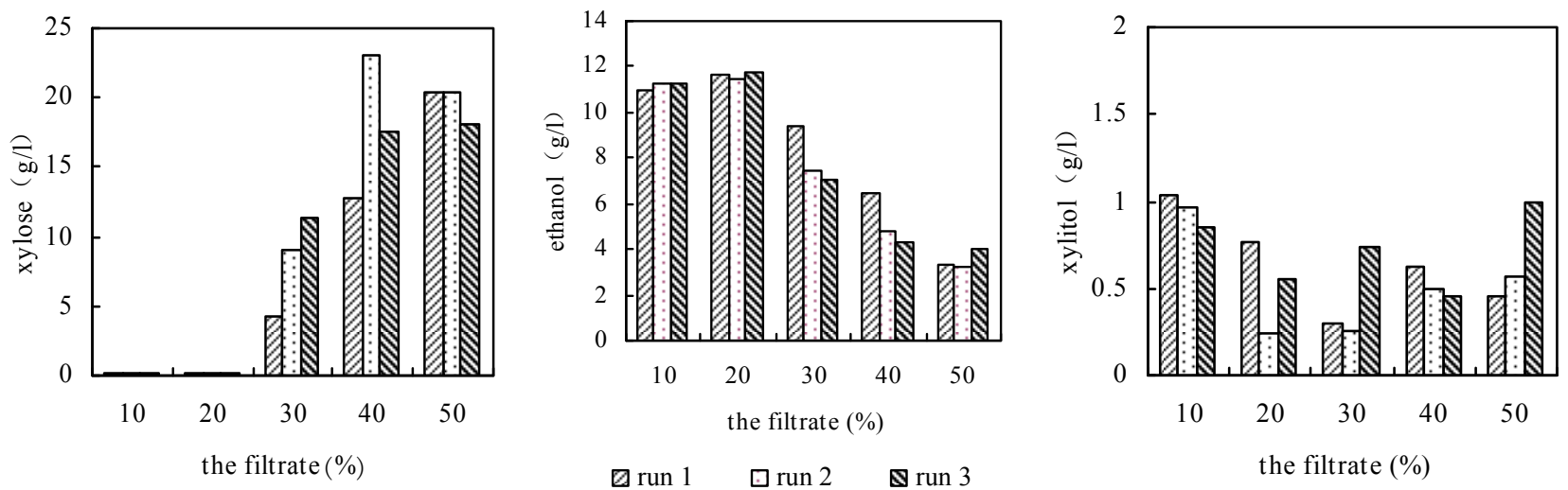

Figure 1. Changes of the concentrations of residue xlose, ethanol and xylitol adapted fermentation in $10 \%, 20 \%, 30 \%$, $40 \%$, and $50 \%$ filtrate for three times by Pichia stipitis CBS 5776 with the addition of xylose $30 \mathrm{~g} / 1$.

From the results of the three times of adaptation fermentation in $10 \%$ to $50 \%$ filtrate by Pichia stipitis CBS 5776 , it could be concluded that the fermentability was decreased gradually with the increasing concentration of the filtrate, especially in $50 \%$ filtrate only $3.55 \mathrm{~g} / 1$ (means of triplicate) ethanol was produced. So Pichia stipitis CBS 5776 endured the concentration of inhibitors had some limitation, only adaptation yeast in the filtrate could not improved the fermentability significantly. Therefore, it was necessary to adopt detoxification methods to detoxify or remove inhibitors in the filtrate in order to further improvement of fermentation.

\subsection{Steam Stripping of the Acid Hydrolyzate and the Filtrate}

Steam stripping was considered as one of the physical detoxification methods. It only removed the volatile compounds in the hydrolyzate. The filtrate from steam exploded corn stover was hydrolyzed at a sulfuric acid concentration of $30 \mathrm{~g} / \mathrm{l}$ at $121^{\circ} \mathrm{C}$ for $45 \mathrm{~min}$ as described above. The resulted acid hydrolyzate was then steam stripped for 15, 30, 45, 60, 90, and 120 min, respectively.
At the same time, steam stripping of the filtrate was also investigated. The effects of stripping time on the compositions of detoxified acid hydrolyzate and the filtrate were summarized in Tables $\mathbf{2}$ and 3 .

From Tables 2 and 3, it could be seen that the concentrations of sugars, such as cellobiose, glucose, xylose and arabinose, remained essentially the same as expected. The non-volatile inhibitors, levulinic acid and 5-hydroxymethylfurfural, were not removed as well. On the other hand, the volatile inhibitors, formic acid, acetic acid and furfural, were removed significantly.

The removal of acetic acid was much higher than that of formic acid. And the removal of formic acid in the acid hydrolyzate $(1.07 \mathrm{~g} / \mathrm{l})$ was much more than that in the filtrate $(0.73 \mathrm{~g} / \mathrm{l})$. The possible reason is that the $\mathrm{pKa}$ value of acetic acid (4.75) is higher than that of formic acid (3.75). In the acidic condition (pH1-2), acetic acid is prone to form molecules, which can be removed easily. While in the filtrate, its $\mathrm{pH}$ was 4.00 , the formic acid was existed in ion formation, so it was not easy to remove. With the stripping time going on, the removal of acetic acid and formic acid slowed down gradually because the

Table 2. Effect of stripping time on the composition of detoxified the acid hydrolyzate.

\begin{tabular}{lccccccc}
\hline \multicolumn{1}{c}{ Compound $(\mathrm{g} / \mathrm{l})$} & 0 & $15 \mathrm{~min}$ & $30 \mathrm{~min}$ & $45 \mathrm{~min}$ & $60 \mathrm{~min}$ & $90 \mathrm{~min}$ & $120 \mathrm{~min}$ \\
\hline Cellobiose & 0.12 & 0.11 & 0.12 & 0.12 & 0.12 & 0.12 & 0.12 \\
Glucose & 1.27 & 1.27 & 1.28 & 1.31 & 1.32 & 1.33 & 1.24 \\
Xylose & 2.13 & 2.10 & 2.11 & 2.15 & 2.17 & 2.20 & 2.02 \\
Arabinose & 0.29 & 0.28 & 0.28 & 0.29 & 0.29 & 0.29 & 0.28 \\
Formic acid & 1.82 & 1.49 & 1.34 & 1.06 & 0.97 & 0.81 & 0.75 \\
Acetic acid & 1.93 & 1.41 & 1.09 & 0.70 & 0.58 & 0.42 & 0.37 \\
Levulinic acid & 0.19 & 0.17 & 0.19 & 0.20 & 0.19 & 0.21 & 0.21 \\
5-hydroxymethylfurfural & 0.09 & 0.08 & 0.08 & 0.08 & 0.08 & 0.08 & 0.06 \\
Furfural & 0.18 & 0.00 & 0.00 & 0.00 & 0.00 & 0.00 & 0.00 \\
\hline
\end{tabular}


Table 3. Effect of stripping time on the composition of detoxified the filtrate of steam exploded corn stover.

\begin{tabular}{|c|c|c|c|c|c|c|c|}
\hline Compound (g/l) & 0 & $15 \mathrm{~min}$ & $30 \mathrm{~min}$ & $45 \mathrm{~min}$ & $60 \mathrm{~min}$ & $90 \mathrm{~min}$ & $120 \mathrm{~min}$ \\
\hline Cellobiose & 0.33 & 0.32 & 0.31 & 0.31 & 0.30 & 0.28 & 0.29 \\
\hline Glucose & 0.30 & 0.29 & 0.29 & 0.29 & 0.28 & 0.27 & 0.28 \\
\hline Xylose & 0.79 & 0.80 & 0.80 & 0.80 & 0.76 & 0.74 & 0.76 \\
\hline Arabinose & 0.27 & 0.27 & 0.26 & 0.26 & 0.26 & 0.24 & 0.25 \\
\hline Formic acid & 2.07 & 1.94 & 1.82 & 1.77 & 1.50 & 1.40 & 1.34 \\
\hline Acetic acid & 2.03 & 1.65 & 1.26 & 1.04 & 0.78 & 0.77 & 0.46 \\
\hline Levulinic acid & 0.12 & 0.11 & 0.11 & 0.11 & 0.11 & 0.10 & 0.11 \\
\hline 5-hydroxymethylfurfural & 0.15 & 0.14 & 0.14 & 0.14 & 0.11 & 0.12 & 0.13 \\
\hline Furfural & 0.10 & 0.00 & 0.00 & 0.00 & 0.00 & 0.00 & 0.00 \\
\hline
\end{tabular}

molecule forms of acetic acid and formic acid were reduced with the $\mathrm{pH}$ increasing [27].

According to the results of Tables 2 and 3, it was necessary to hydrolyze the filtrate with dilute sulfuric acid, because it was not only hydrolyzed the oligosaccharides to monosaccharides, but also it could be removed more inhibitors in the hydrolyzate. So in this study, the filtrate was firstly hydrolyzed with $30 \mathrm{~g} / 1$ sulfuric acid at $121^{\circ} \mathrm{C}$ for $45 \mathrm{~min}$, and then a steam stripping time of $120 \mathrm{~min}$ was selected in order to remove more inhibitors. At this condition, $81 \%$ acetic acid and $59 \%$ formic acid were removed, while furfural was stripped off completely.

\subsection{Overliming of the Acid Hydrolyzate}

The effect of detoxification of the acid hydrolyzate by overliming on sugars (cellobiose, glucose, xylose, and arabinose), weak acids (formic, acetic, and levulinic acid), 5-hydroxymethylfurfural and furfural was examined. The $\mathrm{pH}$ was adjusted to 9,10 , and 11 , respectively, and the temperature was set at 40 and $60{ }^{\circ} \mathrm{C}$ for each $\mathrm{pH}$ treatment. The overliming time was $90 \mathrm{~min}$ [28]. The results of detoxification were summarized in Table 4.

As shown in Table 4, the concentration of cellobiose, arabinose, formic acid, acetic acid, levulinic acid and 5-hydroxymethylfurfural were unchanged or changed slightly when treated with $\mathrm{Ca}(\mathrm{OH})_{2}$ to $\mathrm{pH} 9-11$ at 40 and $60^{\circ} \mathrm{C}$. The concentration of xylose and glucose was de- creased at $\mathrm{pH} 11$, especially when higher temperature $(60$ $\left.{ }^{\circ} \mathrm{C}\right)$ was applied. Xylose was more destroyed than glucose; this agreed with Martinez's results [18] in which pentose sugars were less stable than hexose sugars when $\mathrm{pH}$ was increased from 9 to 11 . The concentration of furfural was reduced by treatment with $\mathrm{Ca}(\mathrm{OH})_{2}$. At $\mathrm{pH} 11,41 \%$ and $50 \%$ furfural were removed at 40 and $60^{\circ} \mathrm{C}$, respectively.

The spectrophotometric analyses of different treatments were also listed in Table 4. Absorbance at $280 \mathrm{~nm}$ represents furfural, 5-hydroxymethylfurfural and phenyl ring absorption band in lignin [22]. Compared with the absorbance value at $280 \mathrm{~nm}, 1.93$, of the untreated acid hydrolyzate, the absorbance values of overliming treatment were decreased with the $\mathrm{pH}$ increasing. This indicated that a part of furfural and phenolics had been removed.

\subsection{Detoxification of the Acid Hydrolyzate with a Combination of Steam Stripping and Overliming}

According to the results of steam stripping and overliming, the acid hydrolyzate was then detoxified with a two step method. The acid hydrolyzate was firstly detoxified by steam stripping for $120 \mathrm{~min}$, water was added to maintain the original value, and then the acid hydrolyzate was secondly detoxified by overliming at $\mathrm{pH} 11$ and $60^{\circ} \mathrm{C}$ for 90 min. The composition of the acid hydrolyzate after two step detoxification was listed in Table $\mathbf{5}$.

Table 4. The effect of $\mathrm{pH}$ and temperature on the overliming detoxification of the acid hydrolyzate.

\begin{tabular}{|c|c|c|c|c|c|c|}
\hline \multirow{2}{*}{ Compound } & \multicolumn{3}{|c|}{$40^{\circ} \mathrm{C}$} & \multicolumn{3}{|c|}{$60^{\circ} \mathrm{C}$} \\
\hline & $\mathrm{pH} 9$ & $\mathrm{pH} 10$ & $\mathrm{pH} 11$ & pH9 & $\mathrm{pH} 10$ & pH11 \\
\hline Cellobiose (g/l) & 0.13 & 0.14 & 0.12 & 0.12 & 0.13 & 0.11 \\
\hline Xylose $(\mathrm{g} / \mathrm{l})$ & 2.23 & 2.23 & 2.04 & 2.16 & 2.13 & 1.63 \\
\hline Arabinose (g/1) & 0.27 & 0.27 & 0.27 & 0.27 & 0.27 & 0.26 \\
\hline Formic acid (g/l) & 1.97 & 1.99 & 2.04 & 1.98 & 1.99 & 2.04 \\
\hline Levulinic acid (g/l) & 0.22 & 0.22 & 0.22 & 0.24 & 0.24 & 0.24 \\
\hline 5-hydroxymethylfurfural (g/l) & 0.07 & 0.05 & 0.07 & 0.09 & 0.08 & 0.08 \\
\hline Furfural $(\mathrm{g} / \mathrm{l})$ & 0.17 & 0.16 & 0.10 & 0.16 & 0.14 & 0.08 \\
\hline Absorbance at $280 \mathrm{~nm}$ & 1.57 & 1.56 & 1.35 & 1.63 & 1.48 & 1.36 \\
\hline
\end{tabular}


Table 5. The composition of acid hydrolyzate detoxified with a combination of steam stripping and overliming.

\begin{tabular}{lccc}
\hline \multicolumn{1}{c}{ Compound } & Before detoxification & After steam stripping $^{\mathrm{a})}$ & After overliming $^{\mathrm{b})}$ \\
\hline Cellobiose $(\mathrm{g} / \mathrm{l})$ & 0.12 & 0.07 & 0.07 \\
Glucose $(\mathrm{g} / \mathrm{l})$ & 1.27 & 1.17 & 0.91 \\
Xylose $(\mathrm{g} / \mathrm{l})$ & 2.13 & 1.92 & 1.23 \\
Arabinose $(\mathrm{g} / \mathrm{l})$ & 0.29 & 0.19 & 0.17 \\
Formic acid $(\mathrm{g} / \mathrm{l})$ & 1.82 & 0.59 & 0.65 \\
Acetic acid $(\mathrm{g} / \mathrm{l})$ & 1.93 & 0.35 & 0.38 \\
Levulinic acid $(\mathrm{g} / \mathrm{l})$ & 0.19 & 0.16 & 0.15 \\
5-hydroxymethylfurfural $(\mathrm{g} / \mathrm{l})$ & 0.09 & 0.05 & 0.05 \\
Furfural $(\mathrm{g} / \mathrm{l})$ & 0.18 & 0.01 & 0.01 \\
Absorbance at $280 \mathrm{~nm}$ & 1.93 & 1.11 & 0.93 \\
\hline
\end{tabular}

a) The time of stripping is $120 \mathrm{~min}$; b) The condition of overliming is at pH11 and $60{ }^{\circ} \mathrm{C}$ for $90 \mathrm{~min}$.

From Table 5, it could be seen that the concentrations of formic, acetic acid and furfural were similar to that of steam stripping alone, indicating that overliming had very limited effect on the removal of these compounds [18]. The value of absorbance at $280 \mathrm{~nm}$ was less than that of overliming alone because steam stripping could remove some furfural and phenolics. Sugar concentrations after two step detoxification were lower than both one step treatments even though the original concentration of each sugar was at very low level.

\subsection{Fermentation of the Detoxified and Undetoxified Acid Hydrolyzates}

The fermentability of three kinds of acid hydrolyzate, the undetoxified hydrolyzate, the hydrolyzate treated with steam stripping, and the hydrolyzate treated with a combination of steam stripping and overliming, had been investigated. Since the sugar contents in these hydrolyzates were too low, $45 \mathrm{~g} / 1$ xylose was added. The yeast Pichia stipitis CBS 5776 was used as the biocatalyst. Figs. 2, 3, and 4 illustrated the fermentation courses including the change profiles of glucose, xylose, the product ethanol, the by-product xylitol, and the optical density (OD) of yeast cells.

As shown in Fig. 2, in the fermentation of undetoxified hydrolyzate, the utilization of sugars were very difficult. In $36 \mathrm{~h}$, only $0.68 \mathrm{~g} / 1$ glucose was consumed; after $48 \mathrm{~h}$, the remained $0.30 \mathrm{~g} / \mathrm{l}$ glucose kept untouched. Xylose was utilized very slowly before $48 \mathrm{~h}$, indicating a long period of adaptation was required. When the yeast adapted to the medium, a rapid consumption of xylose was observed, and only $0.60 \mathrm{~g} / \mathrm{l}$ xylose was left at $85 \mathrm{~h}$.

Ethanol, the main fermentation product, was produced in accordance with the consumption of sugars. The concentration of ethanol reached its highest value of 13.25 $\mathrm{g} / \mathrm{l}$ at $85 \mathrm{~h}$ when xylose was utilized nearly completely (Fig. 2). After that ethanol concentration decreased, probably because the yeast used ethanol as the carbon source when the sugars used out. The trend of the formation of xylitol,

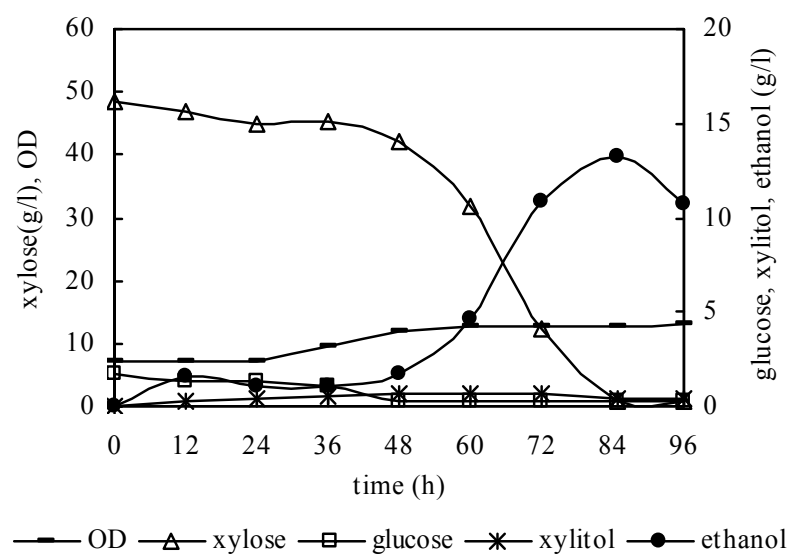

Figure 2. Changes in the parameters during the fermentation of undetoxified acid hydrolyzate with the addition of xylose $45 \mathrm{~g} / \mathrm{l}$.

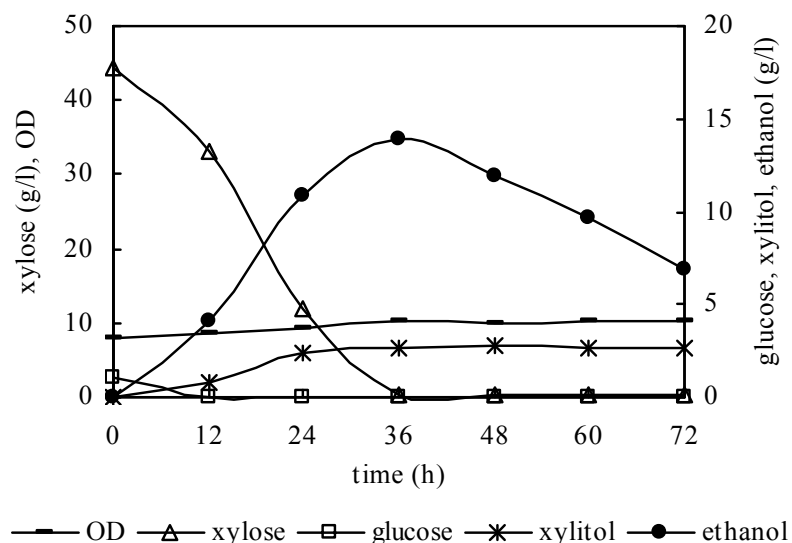

Figure 3. Changes in the parameters during the fermentation of acid hydrolyzate detoxified with steam stripping and the addition of xylose $45 \mathrm{~g} / 1$.

the main by-product, was similar to that of ethanol. At $72 \mathrm{~h}$ xylitol concentration reached its peak of $0.67 \mathrm{~g} / \mathrm{l}$. The OD was increased constantly from 7.35 to 13.10 . 


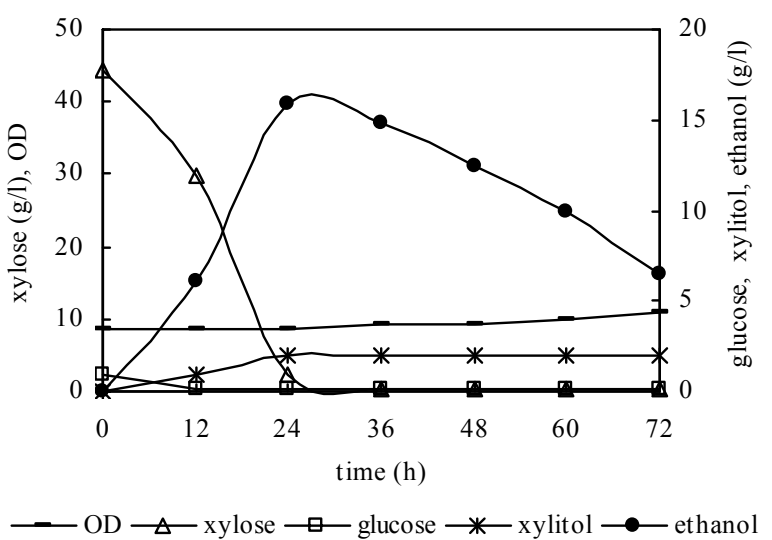

Figure 4. Changes in the parameters during the fermentation of acid hydrolyzate detoxified with a combination of steam stripping and overliming, and the addition of xylose $45 \mathrm{~g} / 1$.

The fermentation of the hydrolyzate treated with steam stripping was more easily than that of undetoxified hydrolyzate as shown in Fig. 3. Glucose was exhausted in 12h. Xylose was consumed rapidly as well; in $36 \mathrm{~h}$ only $0.38 \mathrm{~g} / 1$ xylose was left. Ethanol reached its highest value of $13.91 \mathrm{~g} / \mathrm{l}$ at $36 \mathrm{~h}$, compared to $85 \mathrm{~h}$ in Fig. 2. Xylitol production increased rapidly in $24 \mathrm{~h}$, while the OD was increased constantly from 8.50 to 10.43 . Compared with Fig. 2, the fermentablity of the hydrolyzate treated with steam stripping was improved significantly.

In the fermentation of the hydrolyzate treated with a combination of steam stripping and overliming, the sugar utilization and ethanol production were further improved compared with Fig. 3. As shown in Fig. 4, glucose was exhausted in $12 \mathrm{~h}$, while xylose was consumed substantially in $24 \mathrm{~h}$ with a remaining concentration of $2.28 \mathrm{~g} / \mathrm{l}$. The peak of ethanol concentration, 15.92 $\mathrm{g} / \mathrm{l}$, which was $80.34 \%$ of theoretical, appeared at $24 \mathrm{~h}$, a reasonable fermentation time for practical applications.

From the data above (Figs. 2, 3, and 4), it could be concluded that it is necessary to detoxify the acid hydrolyzate in order to ferment the sugars to ethanol. Steam stripping is an efficient method to detoxify the hydrolyzate. If combined with overliming, steam stripping could significantly improve the fermentability of the hydrolyzate in terms of sugar utilization and ethanol production.

\section{CONCLUSIONS}

The ability of yeast Pichia stipitis CBS 5776 adapted gradually on the fermentation medium containing the filtrate of steam exploded was so limited that detoxification methods must be adopted to remove these inhibitors existed in the filtrate. A combination of steam stripping and overliming was an effective method to remove the inhibitors in the steam exploded corn stover prehydrolyzate, and could improve the fermentability of Pichia stipitis CBS 5776. Steam stripping could remove volatile compounds and at a stripping time of $120 \mathrm{~min}, 81 \%$ acetic acid and 59\% formic acid were removed while furfural was stripped off completely from the acid hydrolyzate. Overliming could reduce the contents of furfural and phenolics presented in the acid hydrolyzate, however, sugars, especially pentoses, were also removed partially. When the acid hydrolyzate detoxified with a combination of steam stripping for $120 \mathrm{~min}$ and overliming at $\mathrm{pH} 11$ and $60^{\circ} \mathrm{C}$ for $90 \mathrm{~min}$, its fermentability was significantly improved. Xylose was consumed nearly completely in $24 \mathrm{~h}$ with an ethanol yield of $15.92 \mathrm{~g} / \mathrm{l}$, $80.34 \%$ of theoretical.

\section{ACKNOWLEDGMENTS}

The authors acknowledge the financial supports from National Natura Science Foundation of China (Grant No.30871992), National High Technology Research and Development Program of China (Grant No. 2008AA 05Z401), and Natural Science Foundation of Jiangsu Higher Education of China (Grant No. 06KJA22015).

\section{REFERENCES}

[1] Saha, B. C., Iten, L. B., Cotta, M. A. and Wu, Y. V. (2005) Dilute acid pretreatment, enzymatic saccharification and fermentation of wheat straw to ethanol. Proc. Biochem. 40, 3693-3700.

[2] Lloyd, T. A. and Wyman, C. E. (2005) Combined sugar yields for dilute sulfuric acid pretreatment of corn stover followed by enzymatic hydrolysis. Bioresour. Technol., 96, 1967-1977.

[3] Carrillo, F., Lis, M. J., Colom, X., Valldeperas, M. and Valldeperas, J. (2005) Effect of alkali pretreatment on cellulose hydrolysis of wheat straw: Kinetic study. Proc. Biochem., 40, 3360-3364.

[4] Kapoor, M., Nair, L. M. and Kuhad, R. C. (2008) Cost-effective xylanase production from free and immobilized Bacillus pumilus strain MK001 and its application in saccharification of Prosopis juliflora. Biochem. Eng. J., 38, 88-97.

[5] Viola, E., Cardinale, M., Santarcangelo, R., Villone, A. and Zimbardi, F. (2008) Ethanol from eel grass via steam explosion and enzymatic hydrolysis. Biomass Bioenerg., 32, 613-618

[6] Teymouri, F., Laureano-Perez, L., Alizadeh, H. and Dale, B. E. (2005) Optimization of the ammonia fiber explosion (AFEX) treatment parameters for enzymatic hydrolysis of corn stover. Bioresour. Technol., 96, 2014- 2018.

[7] Saha, B. C. and Cotta, M. A. (2008) Lime pretreatment, enzymatic saccharification and fermentation of rice hulls to ethanol. Biomass Bioenerg., 32, 971-977.

[8] Klinke, H. B., Thomsen, A. B. and Ahring, B. K. (2001) Potential inhibitors from wet oxidation of wheat straw and their effect on growth and ethanol production by Thermoanaerobacter mathranii. Appl. Microbiol. Biotechnol., 57, 631-638.

[9] Mosier, N., Hendrickson, R., Ho, N., Sedlak, M. and Ladisch, M. R. (2005) Optimization of pH controlled liq- 
uid hot water pretreatment of corn stover. Bioresour. Technol., 96, 1986-1993.

[10] Xu, F., Sun, J. X., Liu, C. F. and Sun, R. C. (2006) Comparative study of alkali-and acidic organic solvent-soluble hemicellulosic polysaccharides from sugarcane bagasse. Carbohyd. Res., 341, 253-261.

[11] Singh, P., Suman, A., Tiwari, P., Arya, N., Gaur, A. and Shrivastava, A. K. (2008) Biological pretreatment of sugarcane trask for its conversion to fermentable sugars. World J. Microbiol. Biotechnol., 24, 667-673.

[12] McMillan, J. D. (1994) Pretreatment of lignocellulosic biomass. In: Himmel, M. E., Baker, J. O., Overend, R. P. (Eds), Enzymatic conversion of biomass for fuels production. American Chemical Society, Washington, DC, 292-324.

[13] Ohgren, K., Galbe, M. and Zacchi, G. (2005) Optimization of steam pretreatment of $\mathrm{SO}_{2}$-impregnated corn stover for fuel ethanol production. Appl. Biochem. Biotechnol., 124, 1055-1067.

[14] Zhu, J., Yong, Q., Chen, S., Xu, Y., Zhang, X. and Yu, S. (2008) Identification of degraded products during corn stover steam-explosion pretreatment. Chemistry and Industry of Forest Products, 29(2), 22-26.

[15] Roberto, I. C., Lacis, L. S., Barbosa, M. F. S. and de Mancilha, I. M. (1991) Utilization of sugar cane bagasse hemicellulosic hydrolysate by Pichia stipitis for the production of ethanol. Proc. Biochem., 26, 15-21.

[16] Nigam, J. N. (2001) Development of xylose-fermenting yeast Pichia stipitis for ethanol production through adaptation on hardwood hemicellulose acid prehydrolysate. J. Appl. Microbiol., 90, 208-215.

[17] Yu, Z. and Zhang, H. (2003) Pretreatments of cellulose pyrolysate for ethanol production by Saccharomyces cerevisiae, Pichia sp. YZ-1 and Zymomonas mobilis. Biomass Bioenerg., 24, 257-262.

[18] Martinez, A., Rodriguez, M. E., York, S. W., Preston, J. F. and Ingram, L. O. (2000) Effects of $\mathrm{Ca}(\mathrm{OH})_{2}$ treatments ("overliming") on the composition and toxicity of bagasse hemicellulose hydrolysates. Biotechnol. Bioeng., 69(5), 526-536.
[19] Yu, S., Wayman, M. and Parekh, S. K. (1987) Fermentation to ethanol of pentose-containing spent sulphite liquor. Biotechnol. Bioeng., 29, 1144-1150.

[20] Chandel, A. K., Kapoor, R. K., Singh, A. and Kuhad, R. C. (2007) Detoxification of sugarcane bagasse hydrolysate improves ethanol production by Candida shehatae NCIM 3501. Bioresour. Technol., 98, 1947-1950.

[21] Miyafuji, H., Danner, H., Neureiter, M., Thomasser, C., Bvochora, J., Szolar, O. and Braun, R. (2003) Detoxification of wood hydrolysates with wood charcoal for increasing the fermentability of hydrolysates. Enzyme Microb. Technol., 32, 396-400.

[22] Jönsson, L. J., Palmqvist, E., Nilvebrant, N. O. and Hahn-Hägerdal, B. (1998) Detoxification of wood hydrolysates with laccase and peroxidase from white-rot fungus Trametes versicolor. Appl. Microbiol. Biotechnol., 49, 691-697.

[23] Olsson, L. and Hahn-Hägerdal, B. (1996) Fermentation of lignocellulosic hydrolysates for ethanol production. Enzyme Microb. Technol., 18, 312-331.

[24] Larsson, S., Reimann, A., Nilvebrant, N. O. and Jönsson, L. J. (1999) Comparison of different methods for the detoxification of lignocellulose hydrolyzates of spruce. Appl. Biochem. Biotechnol., 77-79, 91-103.

[25] Yu, S., Jeppsson, H. and Hahn-Hägerdal, B. (1995) Xylulose fermentation by Saccharomyces cerevisiae and xylose-fermenting yeast strains. Appl. Microbiol. Biotechnol., 44, 314-320.

[26] Saddler, J. N., Ramos, L. P. and Breuil, C. (1993) Steam pretreatment of lignocellulosic residues. In: Bioconversion of forest and agricultural plant residues (Saddler, J. N., Ed.). CAB International Wallingford. UK, 73-91.

[27] Palmqvist, E. and Hahn-Hägerdal, B. (2000) Fermentation of lignocellulosic hydrolysates. II: inhibitors and mechanisms of inhibition. Bioresour. Technol., 74, 25-33.

[28] Purwadi, R., Niklasson, C. and Taherzadeh, M. J. (2004) Kinetic study of detoxification of dilute-acid hydrolyzates by $\mathrm{Ca}(\mathrm{OH})_{2}$. J. Biotechnol., 114, 187-198. 